\title{
Spatial variations in the Kuroshio nutrient transport from the East China Sea to south of Japan
}

\author{
X. Y. Guo ${ }^{1,2}$, X.-H. Zhu ${ }^{1,3}$, Y. Long ${ }^{1}$, and D. J. Huang ${ }^{1,3}$ \\ ${ }^{1}$ State Key Laboratory of Satellite Ocean Environment Dynamics, Second Institute of Oceanography, State Oceanic \\ Administration, Hangzhou 310012, China \\ ${ }^{2}$ Center for Marine Environmental Study, Ehime University, 2-5 Bunkyo-cho, Matsuyama 790-8577, Japan \\ ${ }^{3}$ Department of Ocean Science and Engineering, Zhejiang University, Hangzhou 310058, China
}

Correspondence to: X.-H. Zhu (xhzhu@sio.org.cn)

Received: 28 March 2013 - Published in Biogeosciences Discuss.: 16 April 2013

Revised: 23 August 2013 - Accepted: 4 September 2013 - Published: 10 October 2013

\begin{abstract}
Based on absolute geostrophic velocity, which was calculated using repeated hydrographic data of 39 cruises from 2000 to 2009 and nitrate concentrations measured in the same areas from 1964 to 2009, we obtained the temporally averaged nitrate flux (the product of velocity and nitrate concentration) and nitrate transport (integration of flux over one section) of four sections across the Kuroshio from the East China Sea (sections PN and TK) to an area south of Japan (sections ASUKA and 137E). In addition, we examined section OK east of the Ryukyu Islands in order to understand how the Ryukyu Current contributes to the transport of nutrients by the Kuroshio south of Japan. The mean nitrate flux shows a subsurface maximum core with values of 9.6, 10.6, 11.2, 10.5, and $5.7 \mathrm{~mol} \mathrm{~m}^{-2} \mathrm{~s}^{-1}$ at sections PN, TK, ASUKA, 137E, and OK, respectively. The depth of the subsurface maximum core changes among these five sections and is approximately 400, 500, 500, 400, and $800 \mathrm{~m}$ at sections PN, TK, ASUKA, 137E, and OK, respectively. The mean downstream nitrate transport is 204.8, 165.8, 879.3, 1230.4 , and $338.6 \mathrm{kmol} \mathrm{s}^{-1}$ at sections PN, TK, ASUKA, $137 \mathrm{E}$, and $\mathrm{OK}$, respectively. The transport of nutrients in these sections suggests the presence of the Kuroshio nutrient stream from its upstream to downstream regions. The deep current structure of the Ryukyu Current (section OK) contributes to the same order of nitrate transport as does the Kuroshio from the East China Sea (section TK) to the area south of Japan; however, the former only has one-fifth the volume transport of the latter. A budget calculation suggests that the downstream increase of transported nitrate along the Kuroshio is mainly caused by the recirculation of nitrate
\end{abstract}

into the Kuroshio. This conclusion, however, depends on water depth. In the upper layers $\left(<26.5 \sigma_{\theta}\right)$, the downstream change of nitrate concentration along the Kuroshio and that from the recirculation of nitrate has a significant contribution to the downstream increase of nitrate transport along the Kuroshio. In the deep layers $\left(>26.5 \sigma_{\theta}\right)$, the change in nitrate concentration is small and the Kuroshio recirculation dominates the downstream increase of nitrate transport.

\section{Introduction}

Strong western boundary currents carry large masses of water and amounts of heat as well as a variety of dissolved materials including nutrients, and have a significant influence on the climate and marine ecosystems in the vicinity of their path. Quantitation of nutrient transport by the western boundary current is an important step to understand the nutrient element cycle on a basin scale. Pelegrí and Csanady (1991) and Pelegrí et al. (1996) reported a subsurface maximum in the nutrients flux (the product of velocity and nutrients concentration) and a nitrate transport (integration of flux over a section) with an order of $1000 \mathrm{kmol} \mathrm{s}^{-1}$ in the Gulf Stream, and first proposed the presence of a nutrient stream, a continuous nutrient transport, along the Gulf Stream from its upstream to its downstream areas.

As current speed is reduced, and since nutrient concentration increases as depth increases, the nutrient flux reaches a high subsurface value (Pelegrí and Csanady, 1991). Based on data from four cruises, Chen et al. $(1994,1995)$ calculated 
the nutrient flux of a section of the Kuroshio that is east of Taiwan, and reported the presence of a subsurface maximum core of nutrient flux at a depth of $500 \mathrm{~m}$. Guo et al. (2012) obtained a long-term averaged nutrient flux at section PN (see Fig. 1b for its location) based on data from 88 cruises from 1987 to 2009 and demonstrated a subsurface maximum core of nutrient flux at $400 \mathrm{~m}$ depth in the long-term averaged nutrient flux. Comparing the nutrient fluxes of the section east of Taiwan and at section PN, the depth of the subsurface maximum core of nutrient flux likely changes along the pathway of the Kuroshio. However, except for these two sections, the vertical structure of the nutrient fluxes along the path of the Kuroshio from the East China Sea to south of Japan is unknown.

Guo et al. (2012) reported a value of $170.8 \mathrm{kmol} \mathrm{s}^{-1}$ as the long-term averaged amount of nitrate transported by the Kuroshio along section PN in the East China Sea. This is the only known value of the amount of nutrients transported by the Kuroshio. It is smaller than that observed in the Gulf Stream. As observed in the Gulf Stream, the amount of nitrate that is transported may significantly increase along this stream (Pelegrí and Csanady, 1991; Pelegrí et al., 1996; Williams et al., 2011). Therefore, we also need to investigate the downstream change of nutrient transport by the Kuroshio to (1) confirm the presence of the "Kuroshio nutrient stream" from its upstream to downstream regions and (2) to understand the processes responsible for the downstream variations in nutrient transport by the Kuroshio. In this paper, the nitrate flux and nitrate transport are calculated through four sections across the Kuroshio from its upstream region, the East China Sea (sections PN and TK), to its downstream region, the area south of Japan (sections ASUKA and 137E). In addition, we also examined section OK, which is east of the Ryukyu Islands where the Ryukyu Current is located (Zhu et al., 2004). While examining the nutrient flux and nutrient transport at five sections, our objectives are to confirm the presence of the Kuroshio nutrient stream from the East China Sea to the region south of Japan, reveal the downstream variations of the nutrient flux and nutrient transport along the path of the Kuroshio, and to clarify the factors controlling the spatial variations of the nutrients transported by the Kuroshio.

\section{Data and analysis method}

Conductivity Temperature Depth (CTD) profiler data from winter 2000 to fall 2009 and nutrient data from 1964 to fall 2009 at sections PN, TK, ASUKA, 137E and OK (Fig. 1b) were obtained from the Japan Meteorological Agency (JMA, http://www.data.kishou.go.jp/kaiyou/db/ vessel_obs/data-report/html/ship/ship.php); the nutrient data were from water samples collected at standard depths and analyzed using routine methods (see Table 1 in Aoyama et al. (2008) for details). Figure 2 summarizes the availability

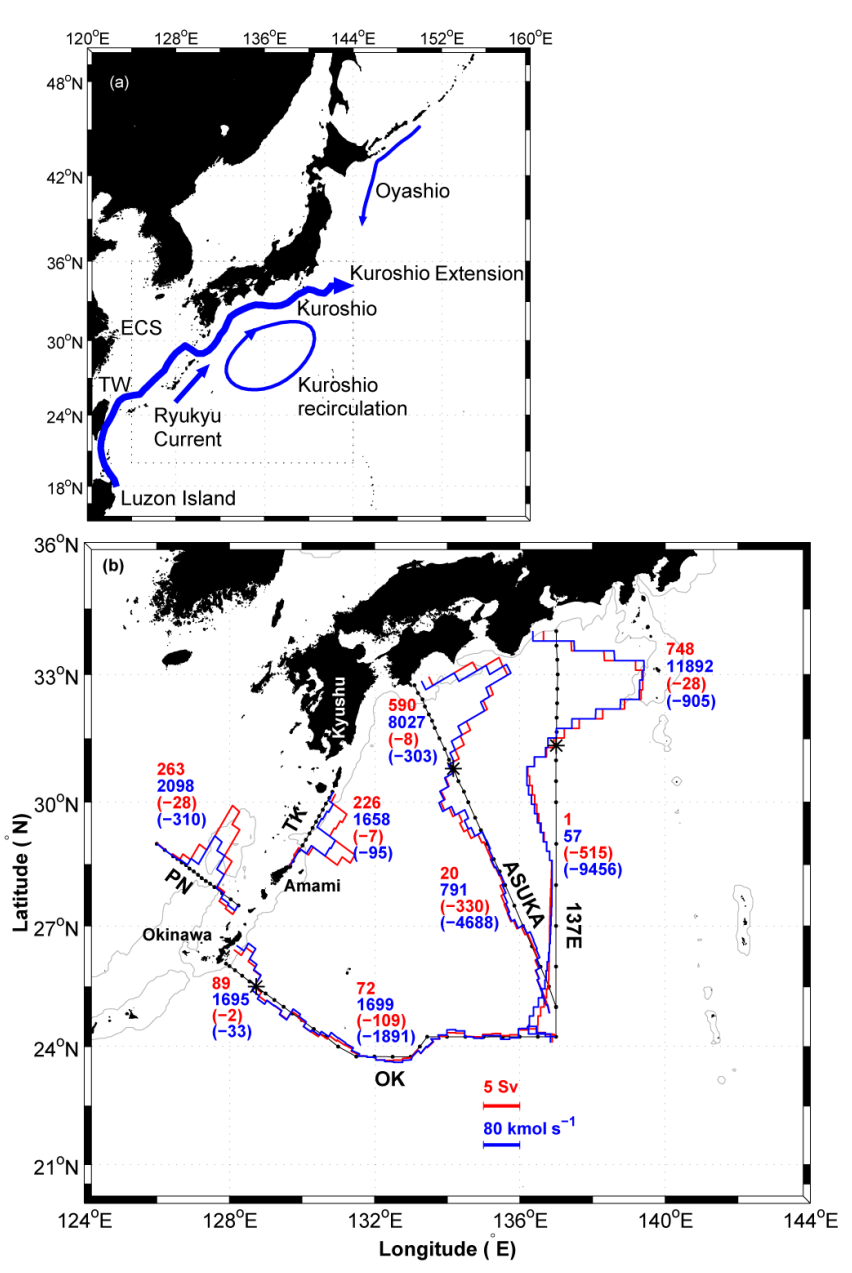

Fig. 1. (a) Study area and schematic image of the Kuroshio path, Kuroshio recirculation, and the Ryukyu Current. ECS: East China Sea; TW: Taiwan. (b) Position of the hydrographic stations (black dots), volume transport (red line, $1 \mathrm{~Sv}=10^{6} \mathrm{~m}^{3} \mathrm{~s}^{-1}$ ) and nitrate transport (blue line, $\mathrm{kmol} \mathrm{s}^{-1}$ ) integrated from the sea surface to the deepest layer with $25 \mathrm{~km}$ width. The positive direction for two transports is defined as the same direction as the Kuroshio or Ryukyu Current. The thin straight lines connecting the black dots serve as a reference point for the transports. For the calculation method of these variables, see Eqs. (4)-(6) and their description in Sect. 2. "PN", "TK", "OK", "ASUKA", and "137E" indicate the names of the sections. The Tokara Strait is located in section TK. The thin curved line denotes the $200 \mathrm{~m}$ isobath. The black asterisks separate section OK into two parts: section OK-W to the west and section OK-E to the east; section ASUKA into two parts: section ASUKA$\mathrm{N}$ to the north and section ASUKA-S to the south; and section 137E into two parts: section 137E-N to the north and section 137E-S to the south. There are four numbers for each section: the two red numbers indicate positive and negative volume transports through the section within a unit of $0.1 \mathrm{~Sv}$, and the two blue numbers indicate positive and negative nitrate transports through the section within a unit of $0.1 \mathrm{kmol} \mathrm{s}^{-1}$. 
Table 1. Along-stream variation of positive volume transport $\mathrm{VT}^{+}(\mathrm{Sv})$ and negative volume transport $\mathrm{VT}^{-}(\mathrm{Sv})$, positive nutrient transport $\mathrm{NT}^{+}\left(\mathrm{kmol} \mathrm{s}^{-1}\right)$ and negative nutrient transport $\mathrm{NT}^{-}\left(\mathrm{kmol} \mathrm{s}^{-1}\right)$, positive transport-averaged nitrate concentration $\mathrm{CT}^{+}\left(\mathrm{mmol} \mathrm{m}^{-3}\right)$ and negative transport-averaged nitrate concentration $\mathrm{CT}^{-}\left(\mathrm{mmol} \mathrm{m}^{-3}\right)$, area-averaged nitrate concentrations for area with positive volume transport $\mathrm{CA}^{+}\left(\mathrm{mmol} \mathrm{m}^{-3}\right)$ and negative volume transport $\mathrm{CA}^{-}\left(\mathrm{mmol} \mathrm{m}^{-3}\right)$, net volume transport $\mathrm{VT}=\mathrm{VT}^{+}+\mathrm{VT}^{-}(\mathrm{Sv})$ and net nutrient transports $\mathrm{NT}=\mathrm{NT}^{+}+\mathrm{NT}^{-}\left(\mathrm{kmol} \mathrm{s}^{-1}\right)$ for each of and total 8 isopycnal layers. The first column is number of layer; the second to sixth columns are one variable for sections PN, TK, OK, ASUKA, and 137E, respectively; the seventh to eleventh columns are another variable for sections PN, TK, OK, ASUKA, and 137E, respectively.

\begin{tabular}{|c|c|c|c|c|c|c|c|c|c|c|}
\hline & $\mathrm{PN}$ & TK & OK & ASUKA & $137 \mathrm{E}$ & $\mathrm{PN}$ & $\mathrm{TK}$ & OK & ASUKA & $137 \mathrm{E}$ \\
\hline & \multicolumn{5}{|c|}{$\mathrm{VT}^{+}(\mathrm{Sv})$} & \multicolumn{5}{|c|}{$\mathrm{VT}^{-}(\mathrm{Sv})$} \\
\hline 1 & 13.7 & 11.4 & 2.5 & 17.1 & 17.2 & -1.2 & -0.5 & -2.9 & -7.0 & -8.7 \\
\hline 2 & 4.7 & 4.4 & 2.6 & 14.0 & 16.2 & -0.5 & 0.0 & -2.0 & -9.3 & -12.3 \\
\hline 3 & 6.1 & 5.0 & 3.9 & 15.5 & 20.3 & -0.6 & 0.0 & -2.2 & -8.4 & -11.8 \\
\hline 4 & 1.6 & 1.5 & 2.4 & 6.8 & 8.9 & -0.4 & 0.0 & -1.1 & -3.5 & -6.1 \\
\hline 5 & 0.2 & 0.3 & 1.9 & 3.2 & 5.2 & -0.2 & 0.0 & -0.9 & -2.2 & -4.6 \\
\hline 6 & 0.0 & 0.0 & 1.4 & 2.0 & 4.1 & 0.0 & -0.2 & -1.0 & -1.6 & -4.8 \\
\hline 7 & 0.0 & 0.0 & 0.7 & 1.2 & 2.0 & 0.0 & 0.0 & -0.6 & -0.9 & -3.3 \\
\hline 8 & 0.0 & 0.0 & 0.7 & 1.0 & 1.0 & 0.0 & 0.0 & -0.5 & -0.9 & -2.6 \\
\hline \multirow[t]{2}{*}{ Total } & 26.3 & 22.6 & 16.1 & 61.0 & 75.0 & -2.8 & -0.7 & -11.2 & -33.8 & -54.2 \\
\hline & \multicolumn{5}{|c|}{$\mathrm{NT}^{+}\left(\mathrm{kmol} \mathrm{s}^{-1}\right)$} & \multicolumn{5}{|c|}{$\mathrm{NT}^{-}\left(\mathrm{kmol} \mathrm{s}^{-1}\right)$} \\
\hline 1 & 23.6 & 15.6 & 2.9 & 43.3 & 35.3 & -1.3 & -0.3 & -2.0 & -5.2 & -6.6 \\
\hline 2 & 33.7 & 26.6 & 15.3 & 86.0 & 111.5 & -2.9 & -0.1 & -10.4 & -44.0 & -62.1 \\
\hline 3 & 93.5 & 70.7 & 61.8 & 249.2 & 338.4 & -8.7 & 0.0 & -33.3 & -126.7 & -185.0 \\
\hline 4 & 45.8 & 42.9 & 74.5 & 202.2 & 262.5 & -11.2 & 0.0 & -34.5 & -107.9 & -186.3 \\
\hline 5 & 8.3 & 10.1 & 73.6 & 123.2 & 194.8 & -7.8 & -1.0 & -33.6 & -84.1 & -181.0 \\
\hline 6 & 0.0 & 0.0 & 55.1 & 83.3 & 168.4 & 0.0 & -8.2 & -40.3 & -65.9 & -198.8 \\
\hline 7 & 0.0 & 0.0 & 29.7 & 50.5 & 81.4 & 0.0 & 0.0 & -24.3 & -37.7 & -133.8 \\
\hline 8 & 0.0 & 0.0 & 25.8 & 41.6 & 38.2 & 0.0 & 0.0 & -19.7 & -34.7 & -103.3 \\
\hline Total & 204.8 & 165.8 & 338.6 & 879.3 & 1230.4 & -31.9 & -9.5 & -198.1 & -506.2 & -1057.0 \\
\hline & \multicolumn{5}{|c|}{$\mathrm{CT}^{+}\left(\mathrm{mmol} \mathrm{m}^{-3}\right)$} & \multicolumn{5}{|c|}{$\mathrm{CT}^{-}\left(\mathrm{mmol} \mathrm{m}^{-3}\right)$} \\
\hline 1 & 1.7 & 1.4 & 1.1 & 2.5 & 2.1 & 1.1 & 0.5 & 0.7 & 0.7 & 0.8 \\
\hline 2 & 7.2 & 6.1 & 5.9 & 6.2 & 6.9 & 6.2 & 4.9 & 5.2 & 4.7 & 5.0 \\
\hline 3 & 15.4 & 14.1 & 15.9 & 16.0 & 16.6 & 15.6 & 0.0 & 15.2 & 15.2 & 15.7 \\
\hline 4 & 28.6 & 28.1 & 30.8 & 29.8 & 29.4 & 29.4 & 0.0 & 30.6 & 30.4 & 30.7 \\
\hline 5 & 36.0 & 34.9 & 38.2 & 38.1 & 37.4 & 36.2 & 36.3 & 38.7 & 38.6 & 38.9 \\
\hline 6 & 0.0 & 0.0 & 40.4 & 40.9 & 40.7 & 0.0 & 39.1 & 40.5 & 41.1 & 41.2 \\
\hline 7 & 0.0 & 0.0 & 40.3 & 40.9 & 40.8 & 0.0 & 0.0 & 40.2 & 41.0 & 41.1 \\
\hline 8 & 0.0 & 0.0 & 39.4 & 40.2 & 40.0 & 0.0 & 0.0 & 39.2 & 40.0 & 40.1 \\
\hline \multirow[t]{2}{*}{ Total } & 7.8 & 7.3 & 21.0 & 14.4 & 16.4 & 11.3 & 12.7 & 17.7 & 15.0 & 19.5 \\
\hline & \multicolumn{5}{|c|}{$\mathrm{CA}^{+}\left(\mathrm{mmol} \mathrm{m}^{-3}\right)$} & \multicolumn{5}{|c|}{$\mathrm{CA}^{-}\left(\mathrm{mmol} \mathrm{m}^{-3}\right)$} \\
\hline 1 & 1.9 & 1.4 & 0.9 & 1.8 & 1.7 & 1.5 & 0.8 & 0.8 & 0.6 & 0.7 \\
\hline 2 & 7.2 & 6.2 & 5.8 & 5.6 & 6.3 & 6.3 & 4.6 & 5.4 & 4.9 & 5.1 \\
\hline 3 & 16.3 & 13.6 & 16.6 & 17.1 & 17.2 & 16.6 & 0.0 & 15.9 & 16.0 & 16.2 \\
\hline 4 & 29.9 & 28.7 & 31.5 & 31.2 & 30.0 & 29.4 & 0.0 & 31.0 & 30.8 & 31.0 \\
\hline 5 & 36.4 & 35.3 & 39.0 & 38.8 & 37.8 & 36.3 & 36.4 & 38.9 & 38.9 & 39.2 \\
\hline 6 & 0.0 & 0.0 & 40.7 & 41.2 & 40.8 & 0.0 & 39.1 & 40.6 & 41.2 & 41.3 \\
\hline 7 & 0.0 & 0.0 & 40.2 & 41.0 & 40.8 & 0.0 & 0.0 & 40.2 & 41.1 & 41.1 \\
\hline 8 & 0.0 & 0.0 & 39.4 & 40.2 & 40.1 & 0.0 & 0.0 & 39.2 & 40.1 & 40.1 \\
\hline Total & 14.5 & 9.7 & 30.8 & 33.5 & 30.0 & 18.4 & 21.7 & 27.2 & 26.7 & 29.6 \\
\hline
\end{tabular}


Table 1. Continued.

\begin{tabular}{|c|c|c|c|c|c|c|c|c|c|c|}
\hline & PN & TK & $\mathrm{OK}$ & ASUKA & $137 \mathrm{E}$ & PN & TK & $\mathrm{OK}$ & ASUKA & $137 \mathrm{E}$ \\
\hline & \multicolumn{5}{|c|}{ VT (Sv) } & \multicolumn{5}{|c|}{$\mathrm{NT}\left(\mathrm{kmol} \mathrm{s}^{-1}\right)$} \\
\hline 1 & 12.5 & 10.9 & -0.4 & 10.1 & 8.5 & 22.3 & 15.3 & 0.9 & 38.1 & 28.7 \\
\hline 2 & 4.2 & 4.4 & 0.6 & 4.6 & 3.9 & 30.8 & 26.5 & 4.9 & 42.0 & 49.4 \\
\hline 3 & 5.5 & 5.0 & 1.7 & 7.2 & 8.5 & 84.8 & 70.7 & 28.5 & 122.4 & 153.3 \\
\hline 4 & 1.2 & 1.5 & 1.3 & 3.2 & 2.9 & 34.5 & 42.9 & 40.0 & 94.4 & 76.2 \\
\hline 5 & 0.0 & 0.3 & 1.1 & 1.1 & 0.6 & 0.5 & 9.1 & 40.0 & 39.1 & 13.8 \\
\hline 6 & 0.0 & -0.2 & 0.4 & 0.4 & -0.7 & 0.0 & -8.2 & 14.7 & 17.4 & -30.4 \\
\hline 7 & 0.0 & 0.0 & 0.1 & 0.3 & -1.3 & 0.0 & 0.0 & 5.4 & 12.8 & -52.5 \\
\hline 8 & 0.0 & 0.0 & 0.2 & 0.2 & -1.6 & 0.0 & 0.0 & 6.0 & 6.9 & -65.1 \\
\hline Total & 23.5 & 21.8 & 4.9 & 27.2 & 20.7 & 172.9 & 156.3 & 140.4 & 373.0 & 173.5 \\
\hline
\end{tabular}

of water temperature, salinity and nutrient data for all five sections.

The CTD data at sections PN, TK, ASUKA, 137E and OK from winter 2000 to fall 2009 (Fig. 2) were used in the inverse calculation of absolute geostrophic velocity. The reason that we limited our analysis to the last $10 \mathrm{yr}$ was to use a consistent average time for all the sections. As shown in Fig. 2, the data at sections ASUKA and OK are highly concentrated during the last decade.

The inverse method (Wunsch, 1978) was applied to the three areas that were enclosed by five sections, the line connecting the two stations at the north end of sections PN and TK, and the coastline of southern Japan (Fig. 1b). The water exchange through two gaps between the islands at the southwestward extension of section TK was neglected. The water column was vertically separated into eight layers bounded by the sea surface and eight isopycnals $(24.80,25.50,26.50$, $\left.27.00,27.30,27.50,27.60,27.66 \sigma_{\theta}\right)$. An approximate mass conservation was assumed within each of the eight layers, while an approximate salt conservation was assumed within the lower seven layers. By allowing small mass and salt unbalances in each layer, an optimum velocity was obtained at the reference level, which was set at a depth of $2000 \mathrm{~m}$ for sections OK, ASUKA, and 137E, $700 \mathrm{~m}$ for sections PN and $\mathrm{TK}$, and at sea bottom if the water depth was shallower than a depth of $2000 \mathrm{~m}$ or $700 \mathrm{~m}$. The optimum reference level for the inverse method to calculate the absolute geostrophic velocity was suggested to be 2000 dbar in the region southeast of the Ryukyu Islands (Yuan et al., 1998; Zhu et al., 2008) and in the Kuroshio region south of Japan (Kaneko et al., 2001), and to be 700 dbar at sections PN and TK (Guo et al., 2012; Wei et al., 2013). After obtaining the velocity at the reference level, the absolute geostrophic velocity normal to the line connecting the two stations at one-meter intervals in the vertical direction was obtained from the thermal winds relation. The absolute geostrophic velocity at one section is denoted as $V(x, z, t)$, where $x$ is the horizontal distance from left side of the section, $z$ is water depth, and $t$ is the time of observations.
To calculate the nutrient flux, the product of velocity and nutrients concentration, the nutrient concentration at the definition point of velocity is also required. The nutrients in the JMA data set have nitrate and phosphate concentrations but not silicate. Since nitrate and phosphate concentrations have a good linear correlation (Guo et al., 2012), the focus of this study is on nitrate. The nitrate concentrations at standard levels were first linearly interpolated at one-meter intervals at the hydrographic stations along each section and were then linearly interpolated horizontally to the definition point of velocity at the same depth, which were set at the middle of two hydrographical stations. The nutrient flux, $F(x, z, t)$ was calculated by using $F(x, z, t)=V(x, z, t) C(x, z, t)$, where $C(x, z, t)$ is nitrate concentration.

It should be noted that the large meander in the Kuroshio significantly changes the nitrate concentration at section 137E. This large meander was observed to form from August 1975 to March 1980, November 1981 to May 1984, December 1986 to July 1988, December 1989 to December 1990, and from July 2004 to August 2005 (http://www.data.kishou.go.jp/kaiyou/shindan/b_ 2/kuroshio_stream/kuroshio_stream.html). During these periods, the area between the meander and coast became large and the nitrate concentration in this area was high. A simple average, without considering the path of the Kuroshio, may induce a pseudo higher nitrate concentration at section 137E. Therefore, the data that were collected during the period of this large meander at section 137E were removed (Fig. 2).

The purpose of this study is to obtain the value of the mean nutrient flux of the Kuroshio at each section during all cruises. As typically done, the direct average of the nutrient flux from each cruise was computed as shown in the following equations:

$F_{0}(x, z)=\frac{1}{N} \sum_{k=1}^{N} F\left(x, z, t_{k}\right)=\frac{1}{N} \sum_{k=1}^{N} V\left(x, z, t_{k}\right) C\left(x, z, t_{k}\right)$,

where $F_{0}(x, z)$ is the mean nutrient flux, subscript $k$ is the time index, and $N$ is the total number of cruises. To calculate $F\left(x, z, t_{k}\right)$, both the current speed and nutrient concentration 


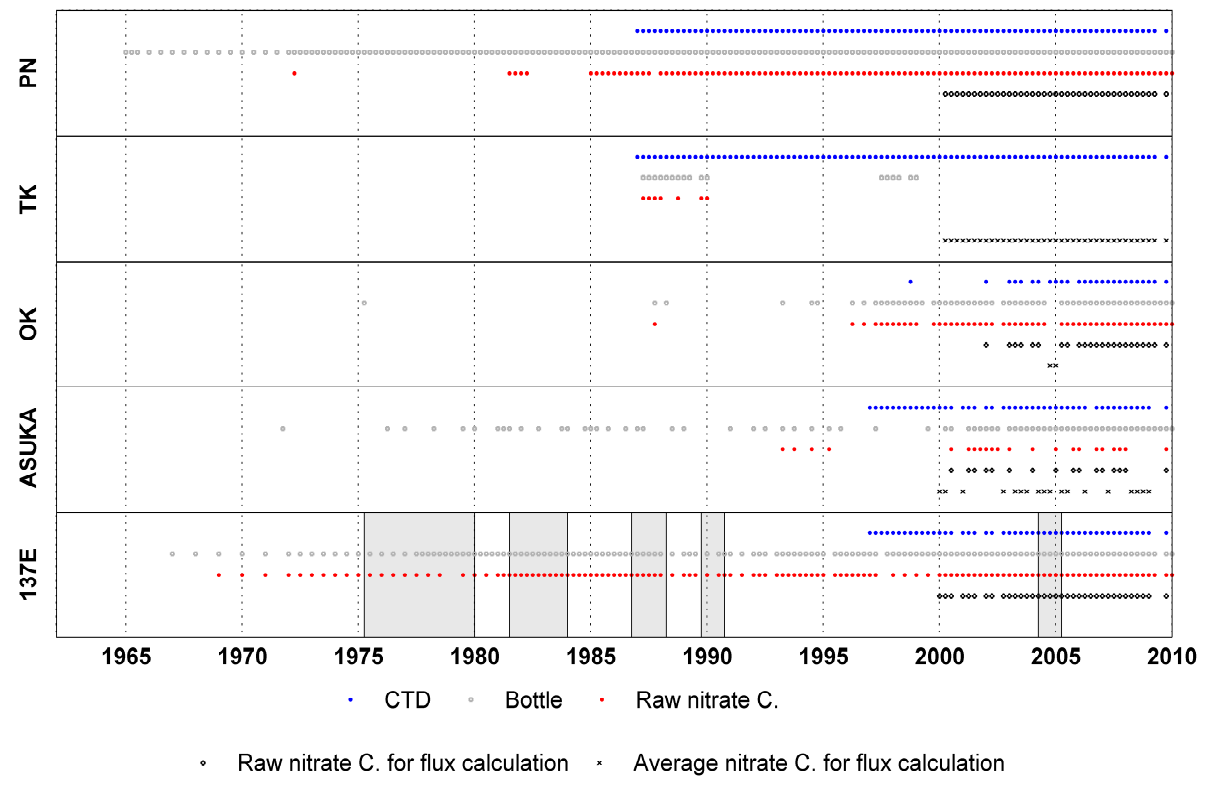

Fig. 2. Data distribution of the five sections. Blue dots denote the CTD data used to calculate velocity; grey circles denote the bottle data for water temperature and salinity; red dots denote the raw nitrate concentration; black circles denote the raw nitrate concentration used to calculate the nitrate flux; black crosses denote the temporally averaged nitrate concentration used to calculate the nitrate flux when the raw nitrate concentration was not available. The grey shading for section 137E denotes the periods when the large meander of the Kuroshio was observed and the data collected during periods were not used in this study.

from the same cruise are needed. However, nitrate concentration was not sampled for section TK from winter 2000 to fall 2009, and was not sufficiently sampled for section ASUKA from winter 2000 to fall 2009 (Fig. 2). Therefore, it is difficult to use Eq. (1) to calculate $F\left(x, z, t_{k}\right)$ for all cruises from winter 2000 to fall 2009 at these two sections. Instead, nitrate concentrations were temporally averaged at the two sections for all cruises that reported a nitrate concentration by using the following equation:

$C_{0}(x, z)=\frac{1}{N_{0}} \sum_{k=1}^{N_{0}} C\left(x, z, t_{k}\right)$,

where $C_{0}(x, z)$ is the mean nitrate concentration and $N_{0}$ is the total number of cruises for the nitrate data at sections TK or ASUKA. $C_{0}(x, z)$ was then used to replace $C\left(x, z, t_{k}\right)$ in Eq. (1) and $F\left(x, z, t_{k}\right)$ was obtained for all cruises from winter 2000 to fall 2009 at the two sections.

However, this replacement introduces an error in the mean nitrate flux $F_{0}(x, z)$. The nutrient concentration at a fixed place during a cruise, $C(x, z, t)$, contains the mean component $C_{0}(x, z)$ and its temporally varying component $C^{\prime}(x, z, t)$, i.e., $C(x, z, t)=C_{0}(x, z)+C^{\prime}(x, z, t)$. Similarly, the current speed at a fixed place during a cruise, $V(x, z, t)$, also has a mean component, $V_{0}(x, z)$, and a temporally varying component, $V^{\prime}(x, z, t)$, i.e., $\quad V(x, z, t)=V_{0}(x, z)+V^{\prime}(x, z, t) \quad$ and $V_{0}(x, z)=\frac{1}{N} \sum_{k=1}^{N} V\left(x, z, t_{k}\right)$. With such separation, the mean nutrient flux becomes

$$
F_{0}(x, z)=V_{0}(x, z) C_{0}(x, z)+\frac{1}{N} \sum_{k=1}^{N} V^{\prime}\left(x, z, t_{k}\right) C^{\prime}\left(x, z, t_{k}\right) .
$$

According to Eq. (3), the mean nutrient flux at a fixed point comprises two components. One is the product of the mean current speed and mean nutrient concentration. The other is the temporal average of the product of temporally varying component of current speed and nutrient concentration. The calculation of $F_{0}(x, z)$ at sections TK and ASUKA neglects the contribution of the second term on the RHS of Eq. (3). This is the first problem when calculating the mean nutrient flux at sections TK and ASUKA. The second problem is the different period used for obtaining the mean nutrient concentration (before 2000) from that used for mean velocity (from winter 2000 to fall 2009) at section TK. As discussed in Sect. 4, these problems do not interfere with the results of this study.

The spatial integral of $F_{0}(x, z)$ at a section used to define the nutrient transport through the section. In order to avoid a pseudo spatial variation of nutrient transport along a section due to the different horizontal distances of the hydrographic stations, $C_{0}(x, z), V_{0}(x, z)$, and $F_{0}(x, z)$ were resampled by dividing a section using a unit width of $25 \mathrm{~km}$ in the horizontal direction and a $1 \mathrm{~m}$ interval in the vertical direction. The resampled variables are denoted as $C_{0}(i, j)$, $V_{0}(i, j)$, and $F_{0}(i, j)$, where $i$ and $j$ are indices in the horizontal and vertical directions, respectively. Based on the resampled variables, three variables were obtained at each of 
the eight isopycnal layers $(l)$ for each section, i.e., spatially averaged nitrate concentrations were obtained for each unit width $C_{0}(i, l)$, volume transport per unit width $\mathrm{VT}_{0}(i, l)$, and nitrate transport per unit width $\mathrm{NT}_{0}(i, l)$, by using the following equations:

$$
\begin{aligned}
& C_{0}(i, l)=\frac{1}{j_{2}-j_{1}+1} \sum_{j=j_{1}}^{j_{2}} C_{0}(i, j) \\
& \mathrm{VT}_{0}(i, l)=\sum_{j=j_{1}}^{j_{2}} V_{0}(i, j) \Delta x \\
& \mathrm{NT}_{0}(i, l)=\sum_{j=j_{1}}^{j_{2}} F_{0}(i, j) \Delta x,
\end{aligned}
$$

where $l$ is the index for eight isopycnal layers, $j_{1}$ and $j_{2}$ are two depth indices for the upper end and lower end of one isopycnal layer, and $\Delta x$ is the unit width $(25 \mathrm{~km})$. The vertical sum of $\mathrm{VT}_{0}(i, l)$ and $\mathrm{NT}_{0}(i, l)$ for $l=1,8$ produces the volume transport $\mathrm{VT}(i)$ and nutrient transport $\mathrm{NT}(i)$ within one unit width along a section. The horizontal sum of $\mathrm{VT}_{0}(i, l)$ and $\mathrm{NT}_{0}(i, l)$ for $i=1, M(M$ is the grid point number of a section in the horizontal direction) produces the total volume transport $\mathrm{VT}(l)$ and nutrient transport $\mathrm{NT}(l)$ for one isopycnal layer of a section; the horizontal sum of $\mathrm{VT}(i)$ and $\mathrm{NT}(i)$ for $i=1, M$ or the vertical sum of $\mathrm{VT}(l)$ and $\operatorname{NT}(l)$ for $l=1,8$ produces the total volume transport VT and total nutrient transport NT through a section.

As presented in Sect. 3, the recirculation south of the Kuroshio is very important to the eastward nutrient transport by the Kuroshio south of Japan. To determine the contribution of this recirculation, positive values for the nutrient flux and nutrient transport are defined at a section if they have the same direction (approximately eastward) as the Kuroshio or Ryukyu Current; negative values are used for the nutrient flux and nutrient transport if they are opposite in direction (approximately westward) compared to the Kuroshio or Ryukyu Current. Superscript "+" ("-") is used to represent positive (negative) velocity, nutrient flux and nutrient transport.

\section{Results}

\subsection{Current fields at the five sections}

The plots of temporally averaged velocity present a consistent image of the Kuroshio from the East China Sea (Fig. 3a and b) to south of Japan (Fig. 3d and e). In the East China Sea, the surface current speed exceeds $1 \mathrm{~m} \mathrm{~s}^{-1}$ above the shelf break at section PN and exhibits a structure with a single maximum speed core around $28.3^{\circ} \mathrm{N}$. The current reduces its speed in proportion to the distance from the maximum speed core in both horizontal and vertical directions. The current speed exceeds $0.1 \mathrm{~m} \mathrm{~s}^{-1}$ at $600 \mathrm{~m}$ depth, showing high potential to carry dissolved material downstream in the subsurface layer.
At the Tokara Strait, which is where the Kuroshio exits the East China Sea, the current shows two maximum speed cores at the southern and northern channels (Fig. 3b). The surface maximum current speed at the Tokara Strait is lower at the northern channel than at the southern channel, and both channels are lower than those at section PN. Although the surface current is weaker at the Tokara Strait than at section $\mathrm{PN}$, the reduction of current speed with depth is also smaller in the Tokara Strait than at section PN. Consequently, a current speed of $0.3 \mathrm{~m} \mathrm{~s}^{-1}$ is maintained at $600 \mathrm{~m}$ depth in the southern channel of the Tokara Strait.

At section ASUKA (Fig. 3d), the Kuroshio is significantly intensified, which may correspond to the large area with a current speed larger than $0.6 \mathrm{~ms}^{-1}$ and the offshore extension of an area with a current speed larger than $0.1 \mathrm{~m} \mathrm{~s}^{-1}$. The eastward volume transport at section ASUKA is 61.0 $\mathrm{Sv}$, which is much larger than that at section PN $(26.3 \mathrm{~Sv})$ and section TK (22.6 Sv) (Table 1). On the other hand, a current with an opposite direction to the Kuroshio can be easily identified south of the Kuroshio. The speed of this counter current is much weaker than the Kuroshio but its presence covers a large area.

The current structure at section 137E (Fig. 3e) is similar with that at section ASUKA, i.e., a strong and robust eastward Kuroshio and a weak but wide westward counter current. However, the distance between the Kuroshio and the coastline at section 137E is greater than that of section ASUKA. A counter coastal current appears at the inshore side of the Kuroshio at section 137E (Fig. 3e).

The current is weak in the surface layer but strong in the subsurface at section OK (Fig. 3c). This is a well-known feature of the Ryukyu Current (Zhu et al., 2004), which is a branch current of the Kuroshio in the East China Sea (Andres et al., 2008). Although it is not very clear in Fig. 3d, a maximum speed core can be identified at $600 \mathrm{~m}$ depth. The eastward volume transport is $16.1 \mathrm{~Sv}$ at section OK.

The eastward volume transport of the Kuroshio is $26.8 \mathrm{~Sv}$ at section PN and $23.5 \mathrm{~Sv}$ at section TK, and changes only slightly in the East China Sea. The combination of the eastward volume transport at sections TK and OK is $\sim 40.0 \mathrm{~Sv}$, which is less than that at section ASUKA (61.0 Sv). Although sections ASUKA and 137E are both located south of Japan and not far from each other, the eastward volume transport increased by $14.0 \mathrm{~Sv}$ from section ASUKA to section 137E (75.0 Sv; Table 1).

The increasing eastward volume transport of the Kuroshio south of Japan is caused by the counter current south of the Kuroshio, i.e., the Kuroshio recirculation. The eastward volume transport of the Kuroshio south of Japan consists of two parts: one is related to basin-scale wind stresses and the other is related to the anticyclonic recirculation gyre, which is a local current system south of the Kuroshio (Hasunuma and Yoshida, 1978). Imawaki et al. (2001) indicated that the recirculation played a significant role in the eastward volume transport of the Kuroshio measured at section 

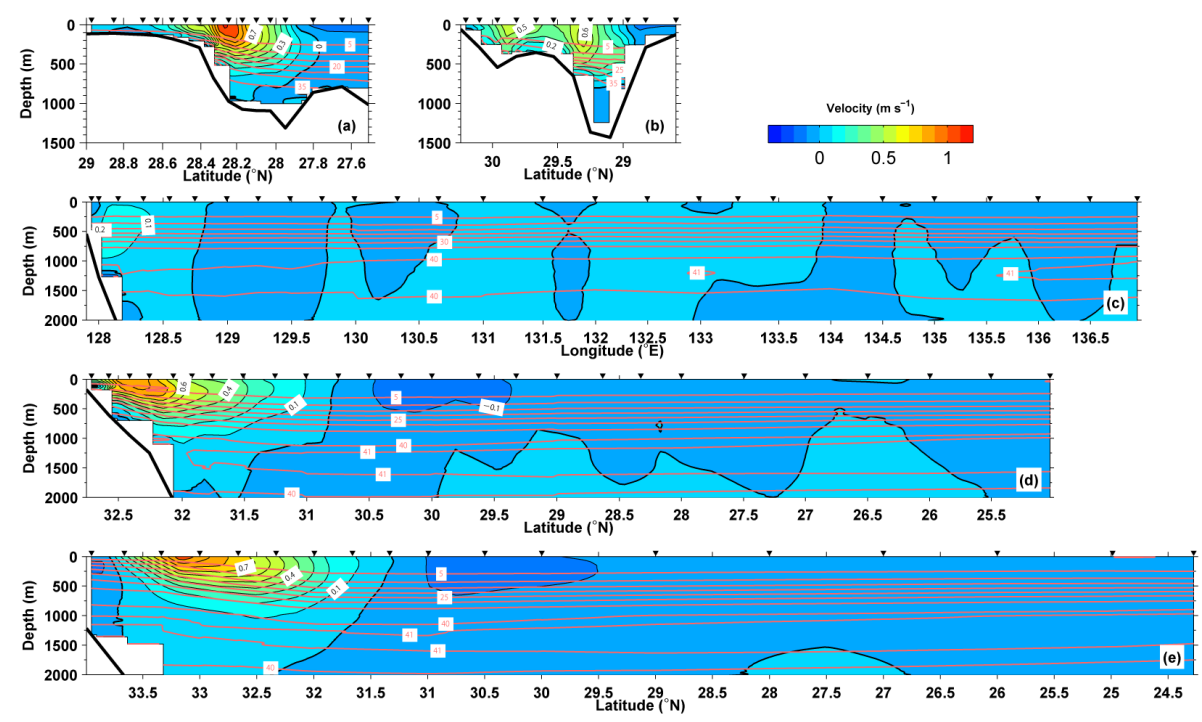

Fig. 3. Temporally averaged absolute geostrophic velocity $\left(\mathrm{ms}^{-1}\right)$ and nitrate concentration $\left(\mathrm{mmol} \mathrm{m}^{-3}\right)$ for all five sections. Colored areas and black contours show velocity with an interval of $0.1 \mathrm{~m} \mathrm{~s}^{-1}$. Positive values are defined as the direction of the Kuroshio or Ryukyu Current. Red contours indicate nitrate concentrations at an interval of $5 \mathrm{mmol} \mathrm{m}^{-3}$, with the exception of $41 \mathrm{mmol} \mathrm{m}^{-3}$. Thick black lines indicate a speed of zero. The inverse triangles denote the hydrographic stations where water temperature, salinity, and nitrate concentrations are available.

ASUKA. Ichikawa et al. (2004) also noted its influences on the Ryukyu Current and attributed the increase in volume transport from section OK (Zhu et al., 2004) to a section southeast of Amami island to the presence of the Kuroshio recirculation.

\subsection{Nitrate concentrations and nitrate fluxes at the five sections}

The temporally averaged nitrate concentration has a relatively simple distribution at the five sections (Fig. 3). In general, nitrate concentration increases with depth: approximately zero at the sea surface, $5 \mathrm{mmol} \mathrm{m}^{-3}$ at $100-200 \mathrm{~m}$ depth, $35 \mathrm{mmol} \mathrm{m}^{-3}$ at $700-800 \mathrm{~m}$ depth, and $\sim 40 \mathrm{mmol} \mathrm{m}^{-3}$ below $1000 \mathrm{~m}$ depth. The vertical varying rate of nitrate concentration is small in the surface layer $(0-200 \mathrm{~m})$, large in the subsurface layer $(200-1000 \mathrm{~m})$, and small in the deep layer $(>1000 \mathrm{~m})$. The horizontal variations in mean nitrate concentration at these sections are found only near the shelf slope where the contour lines of nitrate concentration raise toward the shallow shelf region (Fig. 3).

The temporally averaged nitrate flux has a consistent subsurface maximum core at all five sections (Fig. 4). The depth of the subsurface maximum core is relatively stable along the path of the Kuroshio: $400 \mathrm{~m}$ at section PN, $500 \mathrm{~m}$ at section TK, $500 \mathrm{~m}$ at section ASUKA, and $400 \mathrm{~m}$ at section 137E. However, the corresponding isopycnal layer of the subsurface maximum core slightly changes along the path of the Kuroshio: $25.5-26.5 \sigma_{\theta}$ at section $\mathrm{PN}, \sim 26.5 \sigma_{\theta}$ at section TK, $\sim 26.5 \sigma_{\theta}$ at section ASUKA, and 25.5-26.5 $\sigma_{\theta}$ at section 137E. The subsurface maximum core of nitrate flux at section OK is located at a depth of $800 \mathrm{~m}$, with a corresponding an isopycnal layer of $27.0 \sigma_{\theta}$.

The nitrate flux at its subsurface maximum core is $9.6 \mathrm{mmol} \mathrm{m}^{-2} \mathrm{~s}^{-1}$ at section PN, $10.6 \mathrm{mmol} \mathrm{m}^{-2} \mathrm{~s}^{-1}$ at section TK, $11.2 \mathrm{mmol} \mathrm{m}^{-2} \mathrm{~s}^{-1}$ at section ASUKA, and $10.5 \mathrm{mmol} \mathrm{m}^{-2} \mathrm{~s}^{-1}$ at section 137E, indicating that the values along the path of the Kuroshio are stable. The nitrate flux is $5.7 \mathrm{mmol} \mathrm{m}^{-2} \mathrm{~s}^{-1}$ at section OK. The high nitrate concentration at $800 \mathrm{~m}$ depth is the reason why the Ryukyu Current properly transports nutrients to regions south of Japan, since the current is weak at section OK. In fact, the mean nitrate concentrations at the subsurface maximum core of nitrate flux are 18.3, 26.6, 24.6, 19.7, $36.0 \mathrm{mmol} \mathrm{m}^{-3}$ at sections PN, TK, ASUKA, 137E, and OK, respectively, while the mean speeds at the subsurface maximum core of nitrate flux are $0.50,0.40,0.45,0.53,0.16 \mathrm{~m} \mathrm{~s}^{-1}$ at sections PN, TK, ASUKA, 137E, and OK, respectively.

Since the maximum nitrate flux does not significantly change along the Kuroshio, the nitrate transport through each section should be proportional to the area covered by the same contour of nitrate flux. Furthermore, the area with a nitrate flux larger than $1 \mathrm{mmol} \mathrm{m}^{-2} \mathrm{~s}^{-1}$ significantly increases at sections ASUKA and 137E. Consequently, the eastward nitrate transports are higher at sections ASUKA and 137E than at sections PN, TK, and OK (Table 1).

Up to now, we have only discussed the positive nitrate flux in Fig. 4. However, negative nitrate flux can also be observed at all sections (Fig. 4). This is particularly apparent for sections ASUKA and 137E, where an increase in negative nitrate flux in the subsurface layer is widely observed. This 

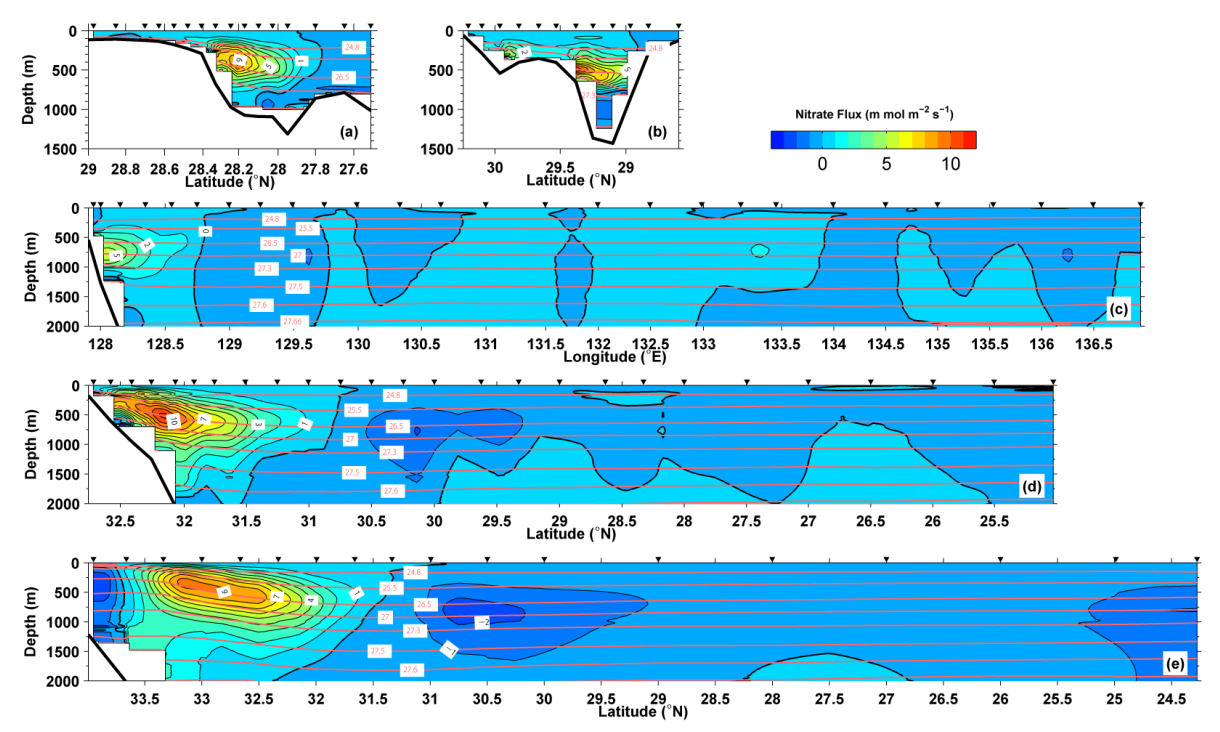

Fig. 4. Temporally averaged nitrate flux $\left(\mathrm{mmol} \mathrm{m}^{-2} \mathrm{~s}^{-1}\right)$ for all sections. Colored areas and black contours indicate the nitrate flux with an interval of $1 \mathrm{mmol} \mathrm{m}^{-2} \mathrm{~s}^{-1}$. Positive values of velocity are defined as in Fig. 3. Red contours indicate the eight isopycnal layers. Thick black lines indicate zero nitrate flux. The inverse triangles are the same as those in Fig. 3.

negative nitrate flux is caused by a weak but broad Kuroshio recirculation south of the Kuroshio (Fig. 4), and this westward nitrate transport also shows a downstream intensification (Table 1).

\subsection{Horizontal distributions of nitrate transport through a defined unit width}

In order to obtain a general image of the horizontal distribution of nutrient transport in the study region, we determined the averaged volume transport $\mathrm{VT}_{0}(i, l)$ and nitrate transport $\mathrm{NT}_{0}(i, l)$ defined by Eqs. (4)-(6) for a defined unit width $(25 \mathrm{~km})$ within each of eight isopycnal layers (Fig. 5). The eastward volume transport is large in the upper layers (Fig. 5a-c) but small in the lower layers (Fig. 5fh). The counter current is apparent at sections ASUKA and 137E, and is located just south of the eastward Kuroshio (Fig. 5a-c). The nitrate concentration varies mainly in the vertical direction, as determined by the difference between the volume transport and nitrate transport in Fig. 5.

The eastward nitrate transport can be confirmed in the 1st layer (Fig. 5a), appears in the 2nd layer (Fig. 5b) to the 6th layer (Fig. 5f), and weakens in the two heaviest layers (Fig. 5g-h). In the first layer (Fig. 5a), the downstream intensification of the eastward nitrate transport along the path of the Kuroshio is observed from section TK to section ASUKA, but not from section ASUKA to section 137E. However, the downstream intensification of the eastward nitrate transport from section TK to section ASUKA and from section ASUKA to section 137E is evident for layers 2 through 5, while that of section ASUKA to section 137E remains constant for the 6th to 8th layers. On the other hand, the westward nitrate transport is evident for layers 2 through 8. Being similar to the eastward nitrate transport, the westward nitrate transport also intensified from section ASUKA to section 137E.

Because the horizontal variations of nitrate transport are similar among the eight layers, the integration from the 1st layer to the 8th layer (Fig. 1b) does not provide a surprising result. The increase in eastward nitrate transport from the East China Sea to south of Japan as well as the downstream intensification of both the eastward and westward nitrate transports from section ASUKA to section 137E are apparent in Fig. 1b.

\section{Discussion}

\subsection{Error caused by using mean nitrite concentration}

As we described in Sect. 2, the mean nitrate flux at sections TK and ASUKA were obtained by calculating the product of the mean current speed and mean nitrate concentration for different periods. We now use section 137E as an example to examine the error caused by this method.

Figure 6a shows the nitrate flux obtained by calculating the product of the mean current speed and mean nitrate concentration for the same period (2000 to 2009). The difference between Figs. 6a and 4e is presented as Fig. 6b; the difference shown is the contribution of the second term on the RHS of Eq. (3). The spatial structure of the nitrate flux in Fig. 6a is similar to that in Fig. 4e. The maximum difference between the two mean nitrate fluxes is $\sim 0.9 \mathrm{mmol} \mathrm{m}^{-2} \mathrm{~s}^{-1}$ (Fig. 6b), which is less than $10 \%$ of the nitrate flux at the same location shown in Fig. 4e. This result suggests that the contribution of 

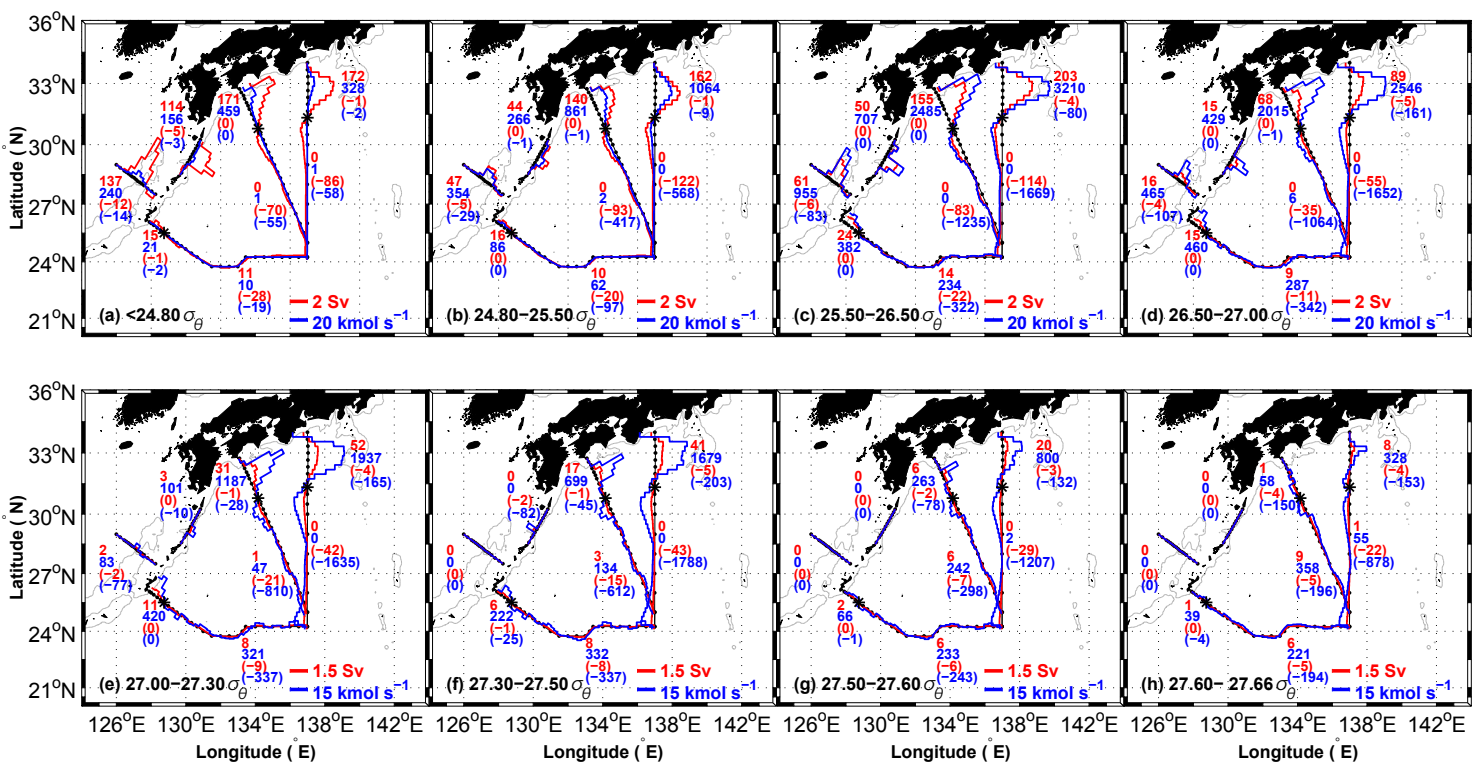

Fig. 5. The same as Fig. 1b, but for each of the eight isopycnal layers: (a) sea surface-24.8的, (b) $24.8-25.5 \sigma_{\theta}$, (c) $25.5-26.5 \sigma_{\theta}$, (d) $26.5-27 \sigma_{\theta}$, (e) $27-27.3 \sigma_{\theta}$, (f) $27.3-27.5 \sigma_{\theta}$, (g) $27.5-27.6 \sigma_{\theta}$, and (h) $27.6-27.66 \sigma_{\theta}$.

the second term on the RHS of Eq. (3) to the mean nitrate flux is smaller than that of the first term on the RHS of Eq. (3) by one order. Therefore, the approximation using only the first term on the RHS of Eq. (3) at sections TK and ASUKA is acceptable.

The second problem with calculating the mean nitrate flux at sections TK and ASUKA is that different periods were used for averaging the current speed and nitrate concentration data. This is not a major problem for section ASUKA but is a significant problem for section TK, where the averaging period for the current speed (2000 to 2009) and that for the nitrate concentration (prior to 1990) are completely different. This treatment not only neglects the second term on the RHS of Eq. (3) but also changes the mean nitrate concentration used in the first term on the RHS of Eq. (3). Figure $6 \mathrm{c}$ shows the nitrate flux that was obtained by calculating the product of the mean current speed from 2000 to 2009 and the mean nitrate concentration from 1970 to 1999 at section 137E. The difference between Figs. $6 \mathrm{c}$ and $4 \mathrm{c}$ is also small (Fig. 6d), suggesting that the influence of using different periods for the mean nitrate concentration and the current speed does not cause a significant change in the mean nitrate flux. Therefore, the mean nitrate fluxes for sections TK and ASUKA, which are presented in Fig. $4 \mathrm{~b}$ and c, are acceptable as a first approximation to the true values.

\subsection{Contribution of the Ryukyu Current and Kuroshio recirculation to the downstream nitrate transport of the Kuroshio}

To quantitatively estimate the nitrate transport at the five sections of this study, the totals of the following items, which are listed in Table 1, were defined for each of the eight isopycnal layers: positive volume transport $\left(\mathrm{VT}^{+}\right)$, positive nutrient transport $\left(\mathrm{NT}^{+}\right)$, positive transport-weighted mean nitrate concentration $\left(\mathrm{CT}^{+}=\mathrm{NT}^{+} / \mathrm{VT}^{+}\right)$, area-weighted mean nitrate concentration for the areas with positive volume transport $\left(\mathrm{CA}^{+}\right)$, negative volume transport $\left(\mathrm{VT}^{-}\right)$, negative nutrient transport $\left(\mathrm{NT}^{-}\right)$, negative transport-weighted mean nitrate concentration $\left(\mathrm{CT}^{-}=\mathrm{NT}^{-} / \mathrm{VT}^{-}\right)$, area-weighted mean nitrate concentration for the areas with negative volume transport $\left(\mathrm{CA}^{-}\right)$, net volume transport $\left(\mathrm{VT}=\mathrm{VT}^{+}+\right.$ $\left.\mathrm{VT}^{-}\right)$, and the net nutrient transports $\left(\mathrm{NT}=\mathrm{NT}^{+}+\mathrm{NT}^{-}\right.$). Since nitrate concentration generally increases with depth while velocity decreases with depth, $\mathrm{CT}^{+}\left(\mathrm{CT}^{-}\right)$is usually smaller than $\mathrm{CA}^{+}\left(\mathrm{CA}^{-}\right)$due to positive vertical shear. In other words, the difference between $\mathrm{CT}^{+}$and $\mathrm{CA}^{+}$or the difference between $\mathrm{CT}^{-}$and $\mathrm{CA}^{-}$reflects the effects of the vertical shear of the current on the nitrate transport.

Sections PN and TK are very similar in structure for all the terms shown in Table 1 . The positive volume transport $\left(\mathrm{VT}^{+}\right)$ and nitrate transport $\left(\mathrm{NT}^{+}\right)$are of the same order for all the isopycnal layers at the two sections, while the negative volume transport $\left(\mathrm{VT}^{-}\right)$and negative nitrate transport $\left(\mathrm{NT}^{-}\right)$ are smaller than the positive volume transport and positive nitrate transport, respectively, by one order. A consistent reduction of $\mathrm{VT}^{+}, \mathrm{NT}^{+}, \mathrm{CT}^{+}, \mathrm{CA}^{+}$from section $\mathrm{PN}$ to section TK can be confirmed in all the isopycnal layers listed in Table 1. The reduction in $\mathrm{VT}^{+}$is consistent with the separation of a northward branch current from the Kuroshio southwest of Kyushu (Lie et al., 1998; Guo et al., 2006). The reduction in $\mathrm{NT}^{+}$from section PN to section TK is caused not only by the reduction in $\mathrm{VT}^{+}$but also by the reduction in $\mathrm{CT}^{+}$. The primary reason for the reduction in $\mathrm{CT}^{+}$is the reduction 


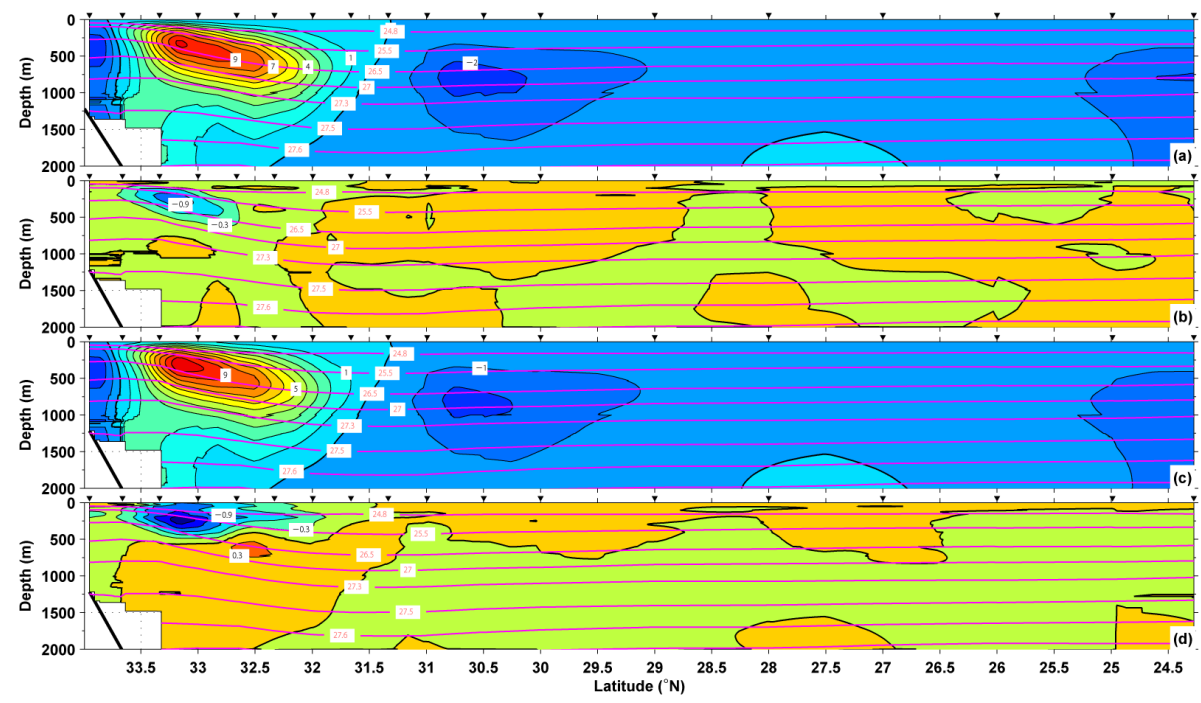

Fig. 6. Nitrate flux $\left(\mathrm{mol} \mathrm{m}^{-2} \mathrm{~s}^{-1}\right.$ ) for section 137E calculated using the temporally averaged speed from 2000 to 2009 , (a) temporally averaged nitrate concentration before 2000, and (c) temporally averaged nitrate concentration from 2000 to 2009. (b) Difference between Fig. 4e and (a); (d) difference between Fig. 4e and (c). Colored areas and black contour lines indicate the nitrate flux with an interval of $1 \mathrm{~mol} \mathrm{~m}^{-2} \mathrm{~s}^{-1}$ in (a) and (c), and with an interval of $0.3 \mathrm{~mol} \mathrm{~m}^{-2} \mathrm{~s}^{-1}$ in (b) and (d). Positive values indicate an eastward flux. Red contour lines indicate the eight isopycnal layers. Thick black lines indicate zero nitrate flux. The inverse triangles are the same as those in Fig. 3.

in $\mathrm{CA}^{+}$from section PN to section TK. The weaker vertical shear of the current at section TK than at section PN (Fig. 3) induces a smaller difference of $\mathrm{CT}^{+}$between the two sections than that of $\mathrm{CA}^{+}$.

The Ryukyu Current plays a more important role in the downstream transport of nitrate than the downstream transport of volume. The positive volume transport $\left(\mathrm{VT}^{+}\right)$is 16.1 Sv at section OK, which is smaller than that at section TK (22.6 Sv; Table 1). However, the positive nitrate transport $\left(\mathrm{NT}^{+}\right)$is $338.6 \mathrm{kmol} \mathrm{s}^{-1}$ at section $\mathrm{OK}$, which is almost two times that at section TK $\left(165.8 \mathrm{kmol} \mathrm{s}^{-1}\right.$; Table 1$)$. The same conclusion is also held for the net nitrate transport (NT) (Table 1). As stated previously, the direct reason for the large nitrate transport at section OK is the deep location of relatively strong current speed, where the nitrate concentration is high (Fig. 3).

Another important issue is the contribution of recirculation, as shown from the values for section OK in Table 1. Differing from sections PN and TK, the negative volume transport $\left(\mathrm{VT}^{-}\right)$and negative nitrate transport $\left(\mathrm{NT}^{-}\right)$at section $\mathrm{OK}$ are of the same order as the positive volume transport $\left(\mathrm{VT}^{+}\right)$and positive nitrate transport $\left(\mathrm{NT}^{+}\right)$, respectively. From the distribution of the nitrate transport for the defined unit width (Fig. 1), we know that the positive nitrate transport is located adjacent to Okinawa Island, which corresponds to the Ryukyu Current, while the negative nitrate transport is widely distributed far from Okinawa Island. Therefore, the second reason that the Ryukyu Current brings more nutrients to the area south of Japan than the Kuroshio in the East China Sea is the contribution of recirculation.
The net volume transport (VT) at section ASUKA is similar to the sum of those at sections TK and OK, but the net nitrate transport (NT) at section ASUKA is larger than the sum of those at sections TK and OK (Table 1). This result indicates an increase of nitrate concentration from section TK and section OK to section ASUKA, which will be examined in the next subsection. Layers 1 through 5 , especially layer 3 $\left(25.50-26.50 \sigma_{\theta}\right)$ and layer $4\left(26.50-27.00 \sigma_{\theta},\right)$, have a major contribution to the net nitrate transport at section ASUKA. The positive and negative nitrate transports are significantly higher at section ASUKA compared to their sum at sections TK and OK, indicating again the apparent contribution of the Kuroshio recirculation to the negative nitrate transport $\left(\mathrm{NT}^{-}\right)$as well as positive nitrate transport $\left(\mathrm{NT}^{+}\right)$. As shown in Fig. 4 and Table 1, the recirculation-induced negative nitrate transport is large in the subsurface of the current (layers 3-5). As a response to the recirculation-induced negative nitrate transport, the positive nitrate transport in these layers also increases. Consequently, the positive nitrate transport at section ASUKA reaches $>1.7$ times the sum of those at sections TK and OK.

Although sections ASUKA and 137E are in close proximity to each other, the positive nitrate transport $\left(\mathrm{NT}^{+}\right)$increased by $50 \%$ from section ASUKA to section 137E (Table 1). Since the positive volume transport $\left(\mathrm{VT}^{+}\right)$only increased by $25 \%$ from section ASUKA to section 137E, the increase of nitrate concentration from section ASUKA to section 137E is expected. However, such a change in nitrate concentration $\left(\mathrm{CT}^{+}\right.$and $\left.\mathrm{CA}^{+}\right)$was only confirmed from the 2 nd layer to the 3 rd layer. The negative nitrate transport $\left(\mathrm{NT}^{-}\right)$is larger at section 137E than at section ASUKA. 
This indicates that a part of the negative nitrate transport returns to the Kuroshio between these two sections. Therefore, a clear image can be drawn for the contribution of the Kuroshio recirculation area that merges into the Kuroshio main stream and increases the positive nitrate transport along the Kuroshio.

\subsection{A budget calculation for water and nutrient transports within each isopycnal layer}

As described in the previous subsection, the Kuroshio recirculation is an apparent cause for the downstream increase of nitrate transport (Table 1). However, the along-stream change of nitrate concentration (Table 1), which is caused by diapycnal mixing and biological processes, must also play a role in the downstream increase of nitrate transport. To quantitate the contributions of the Kuroshio recirculation and downstream change in the nitrate concentration, a budget calculation is conducted for the water and nitrate transports in an area enclosed by two or three sections.

\section{A budget calculation for an area enclosed by section 137E-N and section ASUKA-N}

For this calculation (Fig. 7a), section 137E is divided into two parts and is separated at approximately $31.5^{\circ} \mathrm{N}$ (9th station from the northernmost station in Fig. 1) where the eastward Kuroshio almost disappears. Its northern component (section 137E-N) represents the eastward Kuroshio and its southern component (section 137E-S) represents the westward Kuroshio recirculation. We further divided section 137E-N into two parts: a small northern component (section 137E-N$\mathrm{N})$ that corresponds to a westward coastal current and a large southern component (section 137E-N-S) that corresponds to the Kuroshio. Similarly, section ASUKA is also divided into two parts: a northern component (section ASUKA-N) and a southern component (section ASUKA-S), which is separated at approximately $31^{\circ} \mathrm{N}$ (11th station from the northern most station in Fig. 1).

We denote the volume transport within an isopycnal layer as $V_{1}, V_{2}$, and $V_{\mathrm{C}}$ for sections ASUKA-N, 137E-N-S, and 137E-N-N, respectively (Fig. 7a), and the nitrate transports within the same isopycnal layer are denoted as $\mathrm{NT}_{1}, \mathrm{NT}_{2}$, and $\mathrm{NT}_{\mathrm{C}}$ for sections ASUKA-N, 137E-N-S, and 137E-N-N, respectively. The ratio of $\mathrm{NT}_{1}$ to $V_{1}$ (i.e., transport-weighted mean nitrate concentration) is denoted as $C_{1}$, that of $\mathrm{NT}_{2}$ to $V_{2}$ as $C_{2}$, and that of $\mathrm{NT}_{\mathrm{C}}$ to $V_{\mathrm{C}}$ as $C_{\mathrm{C}}$.

We assume that the difference in the volume transports through sections ASUKA-N and 137E-N is due to the Kuroshio recirculation in the southern region between sections 137E-S and ASUKA-S. The volume transport of the Kuroshio recirculation $\left(V_{\mathrm{R}}\right)$ is therefore $V_{2}-V_{1}-V_{\mathrm{C}}$ and its nitrate transport is given by the production of $V_{\mathrm{R}}$ and the transport-weighted mean nitrate concentration $\left(C_{\mathrm{R}}\right)$ of wa- ter carried by the Kuroshio recirculation. Although the exact value of $C_{\mathrm{R}}$ is unknown, it is reasonable to assume that it is equal to the transport-weighted mean nitrate concentration of the westward water in the same isopycnal layer of section 137E-S, which is the origin of the Kuroshio recirculation water in the area between sections ASUKA-N and 137E-N. The following equation was then obtained:

$$
\begin{aligned}
\mathrm{NT}_{2}-\mathrm{NT}_{1}-\mathrm{NT}_{\mathrm{C}} & =V_{\mathrm{R}} C_{\mathrm{R}}+V_{1}\left(C_{2}-C_{1}\right)+V_{\mathrm{R}}\left(C_{2}-C_{\mathrm{R}}\right) \\
& +V_{\mathrm{C}}\left(C_{2}-C_{\mathrm{C}}\right),
\end{aligned}
$$

where the first term on the RHS, $V_{\mathrm{R}} C_{\mathrm{R}}$, is the nitrate transport via the Kuroshio recirculation, and the other terms arise from the difference in nitrate concentration between each pair of sections and can be attributed to the diapycnal mixing and biological processes occurring over the area between two sections. The values of these terms within each isopycnal layer and for the entire water column are given in Table 2 .

According to Table 2, the nitrate transport by the Kuroshio recirculation accounts for more than $95 \%$ of the downstream increase in nitrate transport for the entire water column. This result, however, does not mean that we can neglect the role of the change in nitrate concentration between two sections. For example, the terms arising from the change in nitrate concentration are more important than the Kuroshio recirculation in the upper two isopycnal layers. In the third isopycnal layer, the Kuroshio recirculation becomes dominant but the terms arising from the change in nitrate concentration between two sections still have a considerable positive contribution. In the deep layers (layers 4-8), the downstream increase of nitrate transport is almost entirely due to the Kuroshio recirculation and the terms arising from the change in nitrate concentration between two sections that have a negative or negligible contribution.

The transport-weighted mean nitrate concentration (Table 2) shows a reduction of nitrate concentration along the Kuroshio from section ASUKA-N $\left(C_{1}\right)$ to section 137E-N$\mathrm{S}\left(C_{2}\right)$ in the first layer. This change is related to the biogeochemical processes that occur over the area between two sections. The nitrate concentrations in the Kuroshio recirculation $\left(C_{\mathrm{R}}\right)$ and in the westward coastal current $\left(C_{\mathrm{C}}\right)$ are also very different than those $\left(C_{1}\right.$ and $\left.C_{2}\right)$ in the Kuroshio, but their contribution to the change in nitrate transport is very small because their volume transport in this layer is small.

The transport-weighted mean nitrate concentration (Table 2) shows an increase in nitrate concentration from section ASUKA-N $\left(C_{1}\right)$ to section 137E-N-S $\left(C_{2}\right)$ and from the Kuroshio recirculation $\left(C_{\mathrm{R}}\right)$ to section $137 \mathrm{E}-\mathrm{N}-\mathrm{S}\left(C_{2}\right)$ in the 2nd and 3rd layers. This increase may be related to the diapycnal mixing that occurs over the area between section ASUKA-N and section 137E-N-S, due to the presence of the downstream reduction of nitrate concentration in the 4 th and 5 th layers between each pair of sections. For layers 4 through 7 , the nitrate concentration is higher in the Kuroshio recirculation $\left(C_{\mathrm{R}}\right)$ than in the two sections of the Kuroshio $\left(C_{1}\right.$ and 

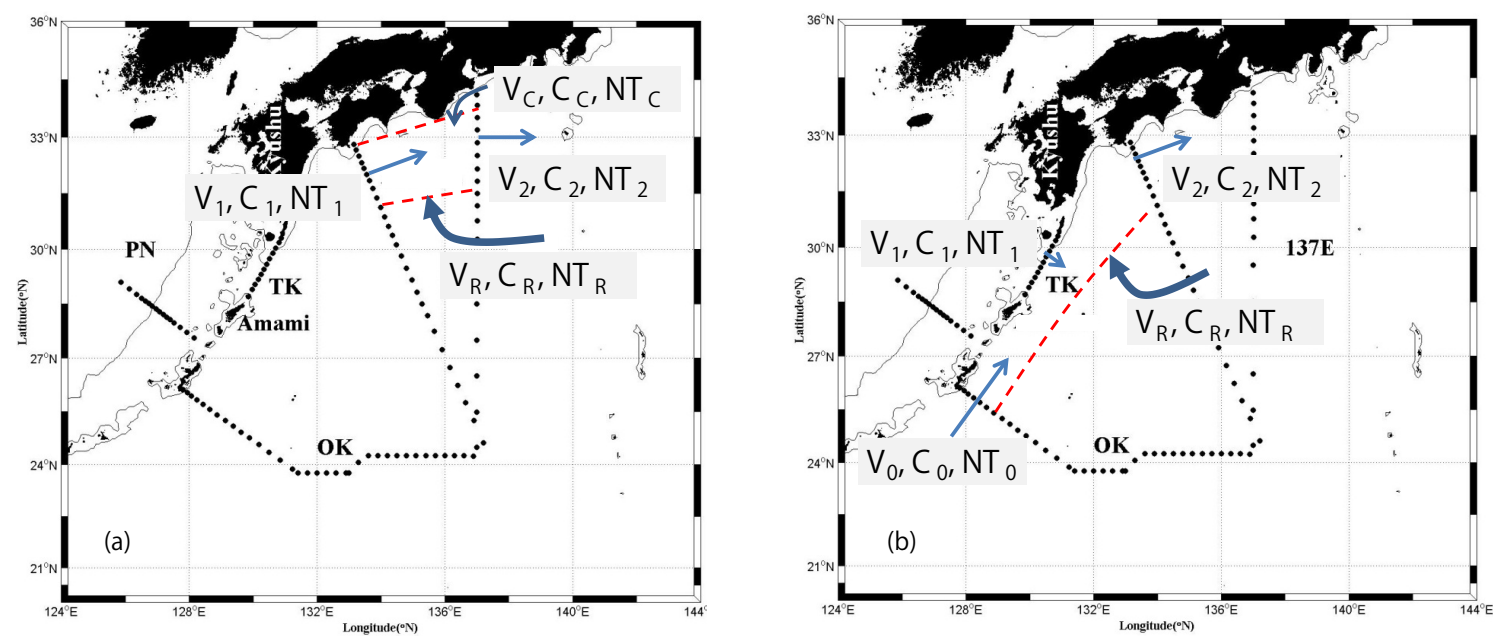

Fig. 7. Schematic of a budget model for an area enclosed by (a) sections ASUKA-N and 137E-N-S and (b) by sections ASUKA-N, TK and OK-W. V: volume transport; NT: nitrate transport; C: ratio of NT to V. (a) Subscript "1" denotes section ASUKA-N; subscript "2" denotes section 137E-N-S; subscript "C" denotes section 137E-N-N where a westward coastal current flows into the area enclosed by sections ASUKA-N and 137E-N-S; and subscript "R" denotes a section (red dashed line) where the Kuroshio recirculation flows into the area enclosed by sections ASUKA-N and 137E-N-S. (b) Subscript "1" denotes section TK; subscript "2" denotes section ASUKA-N; subscript " 0 " denotes section OK-W; and subscript "R" denotes a section (red dashed line) where the Kuroshio recirculation flows into the area enclosed by sections ASUKA-N, TK and OK-W.

Table 2. Budget of nitrate transport $\left(\mathrm{kmol} \mathrm{s}^{-1}\right)$ for each isopycnal layer between sections 137E-N-S and ASUKA-N.

\begin{tabular}{|c|c|c|c|c|c|c|c|c|c|}
\hline Layer & $\begin{array}{r}\mathrm{NT}_{2}-\mathrm{NT}_{1^{-}} \\
\mathrm{NT}_{\mathrm{C}} \\
\left(\mathrm{kmol} \mathrm{s}^{-1}\right)\end{array}$ & $\begin{array}{r}V_{\mathrm{R}} C_{\mathrm{R}} \\
\left(\mathrm{kmol} \mathrm{s}^{-1}\right)\end{array}$ & $\begin{array}{r}V_{1} \\
\left(C_{2}-C_{1}\right) \\
\left(\mathrm{kmol} \mathrm{s}^{-1}\right)\end{array}$ & $\begin{array}{r}V_{\mathrm{R}} \\
\left(C_{2}-C_{\mathrm{R}}\right) \\
\left(\mathrm{kmol} \mathrm{s}^{-1}\right)\end{array}$ & $\begin{array}{r}V_{\mathrm{C}} \\
\left(C_{2}-C_{\mathrm{C}}\right) \\
\left(\mathrm{kmol} \mathrm{s}^{-1}\right)\end{array}$ & $\begin{array}{r}C_{1} \\
\left(\mathrm{mmol} \mathrm{m}^{-3}\right)\end{array}$ & $\begin{array}{r}C_{\mathrm{R}} \\
\left(\mathrm{mmol} \mathrm{m}^{-3}\right)\end{array}$ & $\begin{array}{r}C_{\mathrm{C}} \\
\left(\mathrm{mmol} \mathrm{m}^{-3}\right)\end{array}$ & $\begin{array}{r}C_{2} \\
\left(\mathrm{mmol} \mathrm{m}^{-3}\right)\end{array}$ \\
\hline 1 & -8.2 & 0.0 & -8.1 & 0.0 & -0.1 & 2.5 & 0.7 & 3.0 & 2.1 \\
\hline 2 & 24.8 & 10.7 & 10.2 & 4.0 & -0.1 & 6.1 & 5.0 & 7.5 & 6.9 \\
\hline 3 & 82.7 & 69.0 & 9.3 & 4.6 & -0.2 & 16.0 & 15.6 & 17.1 & 16.6 \\
\hline 4 & 46.8 & 51.6 & -2.6 & -2.4 & 0.2 & 29.8 & 30.8 & 28.9 & 29.4 \\
\hline 5 & 65.3 & 70.2 & -2.0 & -3.0 & 0.1 & 38.1 & 39.1 & 37.3 & 37.4 \\
\hline 6 & 87.0 & 88.2 & 0.0 & -1.2 & 0.0 & 40.7 & 41.3 & 40.8 & 40.7 \\
\hline 7 & 50.8 & 51.1 & 0.0 & -0.3 & 0.0 & 40.8 & 41.1 & 40.8 & 40.8 \\
\hline 8 & 29.9 & 30.0 & 0.0 & 0.0 & 0.0 & 40.6 & 40.1 & 39.8 & 40.1 \\
\hline All & 379.2 & 370.9 & 6.6 & 1.7 & 0.0 & & & & \\
\hline
\end{tabular}

$C_{2}$ ), indicating that remineralization plays an important role in the Kuroshio recirculation.

\section{A budget calculation for an area enclosed by sections ASUKA-N, TK and OK-W}

In a similar way, section OK was divided into two parts at approximately $129^{\circ} \mathrm{E}$ (5th station from the western most station in Fig. 1). The current in its western component (section OK-W) is the Ryukyu Current and the current in its eastern component (section OK-E) is considered to be the Kuroshio recirculation. The budget is calculated in an area surrounded by sections TK, OK-W and ASUKA-N (Fig. 7b). The residual component of the volume transport through three sections is supplied by the Kuroshio recirculation from the area between sections OK-E and ASUKA-S.

The volume transport through sections OK-W, TK and ASUKA-N are denoted as $V_{0}, V_{1}$, and $V_{2}$, respectively. The volume transport of the Kuroshio recirculation $\left(V_{\mathrm{R}}\right)$ is obtained by $V_{\mathrm{R}}=V_{2}-V_{0}-V_{1}$. The nitrate transport through sections OK-W, TK and ASUKA-N is denoted by $\mathrm{NT}_{0}, \mathrm{NT}_{1}$, and $\mathrm{NT}_{2}$, respectively, and their corresponding transportweighted mean nitrate concentrations are $C_{0}, C_{1}$, and $C_{2}$. The nitrate concentration of the Kuroshio recirculation into the area $\left(C_{\mathrm{R}}\right)$ is assumed to be equal to the transportweighted mean nitrate concentration in the westward water current of section ASUKA-S and that in the eastward water current of section OK-E. An equation for the budget in this 
Table 3. Budget of nitrate transport $\left(\mathrm{kmol} \mathrm{s}^{-1}\right)$ for each isopycnal layer between sections TK, OK-W, and ASUKA-N.

\begin{tabular}{|c|c|c|c|c|c|c|c|c|c|}
\hline Layer & $\begin{array}{r}\mathrm{NT}_{2}-\mathrm{NT}_{1}- \\
\mathrm{NT}_{0} \\
\left(\mathrm{kmol} \mathrm{s}^{-1}\right)\end{array}$ & $\begin{array}{r}V_{\mathrm{R}} C_{\mathrm{R}} \\
\left(\mathrm{kmol} \mathrm{s}^{-1}\right)\end{array}$ & $\begin{array}{r}V_{0} \\
\left(C_{2}-C_{0}\right) \\
\left(\mathrm{kmol} \mathrm{s}^{-1}\right)\end{array}$ & $\begin{array}{r}V_{1} \\
\left(C_{2}-C_{1}\right) \\
\left(\mathrm{kmol} \mathrm{s}^{-1}\right)\end{array}$ & $\begin{array}{r}V_{\mathrm{R}} \\
\left(C_{2}-C_{\mathrm{R}}\right) \\
\left(\mathrm{kmol} \mathrm{s}^{-1}\right)\end{array}$ & $\begin{array}{r}C_{0} \\
\left(\mathrm{mmol} \mathrm{m}^{-3}\right)\end{array}$ & $\begin{array}{r}C_{1} \\
\left(\mathrm{mmol} \mathrm{m}^{-3}\right)\end{array}$ & $\begin{array}{r}C_{\mathrm{R}} \\
\left(\mathrm{mmol} \mathrm{m}^{-3}\right)\end{array}$ & $\begin{array}{r}C_{2} \\
\left(\mathrm{mmol} \mathrm{m}^{-3}\right)\end{array}$ \\
\hline 1 & 26.0 & 3.6 & 1.6 & 12.1 & 8.6 & 1.4 & 1.4 & 0.8 & 2.5 \\
\hline 2 & 49.9 & 38.6 & 0.2 & 0.4 & 10.7 & 6.0 & 6.1 & 4.8 & 6.1 \\
\hline 3 & 140.0 & 123.7 & 0.9 & 9.9 & 5.6 & 15.7 & 14.1 & 15.3 & 16.0 \\
\hline 4 & 113.2 & 114.8 & -0.9 & 2.5 & -3.3 & 30.4 & 28.1 & 30.6 & 29.8 \\
\hline 5 & 65.5 & 65.1 & 0.7 & 0.9 & -1.1 & 37.5 & 34.8 & 38.8 & 38.1 \\
\hline 6 & 60.5 & 60.8 & 0.4 & -0.3 & -0.4 & 39.6 & 39.1 & 41.0 & 40.7 \\
\hline 7 & 19.7 & 19.6 & 0.1 & 0.0 & 0.0 & 40.1 & 0.0 & 40.7 & 40.8 \\
\hline 8 & -1.2 & -1.3 & 0.1 & 0.0 & 0.0 & 39.3 & 0.0 & 39.7 & 40.6 \\
\hline All & 473.7 & 425.0 & 3.2 & 25.4 & 20.1 & & & & \\
\hline
\end{tabular}

area was also obtained:

$$
\begin{aligned}
\mathrm{NT}_{2}-\mathrm{NT}_{1}-\mathrm{NT}_{0} & =V_{\mathrm{R}} C_{\mathrm{R}}+V_{0}\left(C_{2}-C_{0}\right)+V_{1}\left(C_{2}-C_{1}\right) \\
& +V_{\mathrm{R}}\left(C_{2}-C_{\mathrm{R}}\right)
\end{aligned}
$$

According to Table 3, in which the values for each term in Eq. (8) are given, the advection of the Kuroshio recirculation $\left(V_{\mathrm{R}} C_{\mathrm{R}}\right)$ is more important than the terms arising from the difference in nitrate concentration between the pairs of sections and the downstream increase of nitrate transport $\left(\mathrm{NT}_{2}-\mathrm{NT}_{1}-\mathrm{NT}_{0}\right)$. The contribution of the Kuroshio recirculation to the downstream increase of nitrate transport for all eight layers is approximately $90 \%$. As with the area enclosed by sections ASUKA-N and 137E-N-S, this does not mean that the role of the terms related to the difference in nitrate concentration between a pair of sections is negligible. For example, the terms that depend on the difference in nitrate concentration between a pair of sections are more important than the Kuroshio recirculation in the first layer (Table 3 ). In the 2 nd and 3rd layers, the terms that depend on the difference in nitrate concentration between a pair of sections are still important. It is only below the 4th layer that the Kuroshio recirculation becomes the only contribution to the downstream increase of nitrate transport.

The downstream increase of nitrate concentration along the pathway of Kuroshio (from section TK to section ASUKA-N) and that from the Kuroshio recirculation to the Kuroshio (section ASUKA-N) in the upper three layers, as well as the downstream reduction of nitrate concentration from the Kuroshio recirculation to the Kuroshio in the deep layers (layers 4-7), were also found for this area. The result is likely a consistent feature in the Kuroshio and Kuroshio recirculation.

Williams et al. (2011) reported that the same downstream intensification of nutrient transport occurred along the Gulf Stream and concluded that the primary cause for the increase in nutrient transport was the recirculation-induced increasing downstream volume transport of the Gulf Stream, while the second cause was the downstream increase of nutrient concentration in the water carried by the denser layers of the Gulf
Stream. The importance of recirculation is similar with our results according to the budget calculation for the two areas in the Kuroshio region. However, the downstream increase in nutrient concentration in denser layers was found only from section Tokara to section ASUKA, and was not found from section OK-W to section ASUKA and from section ASUKA to section 137E. In fact, the downstream changes of nitrate concentration in the denser layers from section $\mathrm{OK}-\mathrm{W}$ to section ASUKA, from section ASUKA to section 137E, and from the Kuroshio recirculation to section ASUKA and section $137 \mathrm{E}$ are generally small or negative.

Williams et al. (2011) reported a downstream decrease in nutrient concentration in the water carried by the lighter layers of the Gulf Stream and confirmed that the lateral water exchange in the same isopycnal layers were the cause for the downstream increase and decrease of nutrient concentration in the water carried by the Gulf Stream. We can confirm that the nitrate concentration is lower in the Kuroshio recirculation than in the light layers (layers 1-3) of the Kuroshio, and that such a dilution effect is not strong enough to induce a lower nitrate concentration in the downstream region than in the upstream region of the Kuroshio main stream due to the relatively smaller volume transport of the Kuroshio recirculation.

Pelegrí and Csanady (1991) also reported a downstream increase of nitrate transport along the Gulf Stream and attributed it to the diapycnal mixing that occurred along the Gulf Stream. Since the results by Pelegrí and Csanady (1991) are similar to the results of our budget calculations (Tables 2 and 3) (i.e., nitrate concentration increased in the light layers and decreased in the dense layers), we believe that diapycnal mixing should be an important factor in controlling the change of nitrate along the Kuroshio. Recently, Kaneko et al. (2013) calculated the vertical nitrate flux in the main stream of the Kuroshio from measured nitrate concentrations and the vertical viscosity coefficient estimated from field turbulent measurements. Their results indicated an upward nitrate flux from the depth of $300 \mathrm{~m}$ to the surface layer. This 
measurement supports our result of a downstream increase of nitrate concentration along the light layers of the Kuroshio.

\section{Summary}

Using repeated hydrographic data from 2000 to 2009 and an inverse method, we obtained the absolute geostrophic current speed at four sections across the Kuroshio from the East China Sea (sections PN and TK) to south of Japan (sections ASUKA and 137E) and at a section southeast of the Ryukyu Islands (section OK). The vertical structures and volume transports of temporally averaged velocity in these sections were generally consistent with previous results regarding the Kuroshio and Ryukyu Current in such locations. In addition, the presence of the Kuroshio recirculation was confirmed for sections OK, ASUKA and 137E.

Using absolute geostrophic current speed and the nitrate concentration measured at all five sections, we then obtained nitrate fluxes and their temporal mean values. The presence of a subsurface maximum core in the nutrient flux, as reported in the Gulf Stream (Pelegrí and Csanady, 1991; Pelegrí et al., 1996) and at section PN (Guo et al., 2012), was confirmed at all sections and their depths were found to be 400, 500, 500, 400, and $800 \mathrm{~m}$ for sections PN, TK, ASUKA, $137 \mathrm{E}$ and $\mathrm{OK}$, respectively, indicating the presence of a stable nutrient stream along the Kuroshio from the East China Sea to south of Japan. The eastward nitrate transport carried by this stable nutrient stream is 204.8, 165.8, 338.6, 879.3, and $1230.4 \mathrm{kmol} \mathrm{s}^{-1}$ for sections PN, TK, OK, ASUKA, and $137 \mathrm{E}$, respectively.

The deepest subsurface maximum core of nitrate flux at section OK was induced by the vertical structure of the Ryukyu Current, whose maximum current speed is in its subsurface (Zhu et al., 2004). This in turn results in a large downstream nitrate transport at section $\mathrm{OK}$, suggesting that a weak but deep Ryukyu Current contributes to the same order of nitrate transport as the strong but shallow Kuroshio that is located in the East China Sea to the region south of Japan.

The Kuroshio recirculation has a significant contribution to the amount of nitrate transport through sections ASUKA and 137E. The eastward nitrate transport from section ASUKA to section 137E increased by a factor of 1.5, the eastward nitrate transport at ASUKA is larger than the sum of those at sections TK and OK by a factor of 1.8. The importance of the Kuroshio recirculation to the downstream increase of nitrate transport, however, does not mean that the physical processes (e.g., diapycnal mixing) and biogeochemical processes that change the nitrate concentration along the pathway of Kuroshio are negligible. A budget calculation within each of the isopycnal layers suggested that the downstream change of nitrate concentration along the pathway of Kuroshio and that from the Kuroshio recirculation to the Kuroshio has a significant contribution to the downstream increase of nitrate transport in the upper layers $\left(<26.5 \sigma_{\theta}\right)$ along the Kuroshio main stream.

The downstream intensification of the nutrient transport is a common feature in the nutrient streams of the Gulf Stream and the Kuroshio. The recirculation and its contribution to the nutrient transport occur in both streams. A special feature in the northwest region of the Pacific is the Ryukyu Current, which has a deep current structure and transports the same order of nutrients as the Kuroshio does from the East China Sea to the region south of Japan. A difference between the Gulf Stream and the Kuroshio is the downstream variation of nutrient concentration in the water carried by the two western boundary currents. Nitrate concentration decreases in the light layers but increases in the dense layers along the Gulf Stream (Williams et al., 2011). However, the downstream variation of the nitrate concentration in the Kuroshio region is not as simple as that of the Gulf Stream. Therefore, more complex processes are expected to occur in the Kuroshio and should be investigated in future studies.

Acknowledgements. This work was supported by the National Natural Science Foundation of China (41176021, 41276028 and 41321004) and the National Basic Research Program of China (2011CB409803 and 2012CB956004). X. GUO is thankful for support from JSPS KAKENHI (21310012) and the Open Fund of Key Laboratory of Marine Ecosystem and Biogeochemistry, SOA (LMEB201107).

Edited by: C.-K. Kang

\section{References}

Andres, M., Park, J.-H., Wimbush, M., Zhu, X.-H., Chang, K.-I., and Ichikawa, H.: Study of the Kuroshio/Ryukyu Current system based on satellite-altimeter and in situ data measurements, J. Oceanogr., 64, 937-950, 2008.

Aoyama, M., Goto, H., Kamiya, H., Kaneko, I., Kawae, S., Kodama, H., Konishi, Y., Kusumoto, K., Miura, H., Moriyama, E., Murakami, K., Nakano, T., Nozaki, F., Sasano, D., Shimizu, T., Suzuki, H., Takatsuki, Y., and Toriyama, A.: Marine biogeochemical response to a rapid warming in the main stream of the Kuroshio in the western North Pacific, Fish. Oceanogr., 17, 206218, 2008.

Chen, C. T. A., Liu, C. T., and Pai, S. C.: Transport of oxygen, nutrients and carbonates by the Kuroshio Current, Chin. J. Oceanol. Limn., 12, 220-227, 1994.

Chen, C. T. A., Liu, C. T., and Pai, S. C.: Variations in oxygen, nutrient and carbonate fluxes of the Kuroshio Current, La mer, 33, 161-176, 1995.

Guo, X., Miyazawa, Y., and Yamagata, T.: The Kuroshio onshore intrusion along the shelf break of the East China Sea: The origin of the Tsushima Warm Current, J. Phys. Oceanogr., 36, 22052231, 2006.

Guo, X., Zhu, X.-H., Wu, Q.-S., and Huang, D.: The Kuroshio nutrient stream and its temporal variation in the East China Sea, J. Geophys. Res., 117, C01026, doi:10.1029/2011JC007292, 2012. 
Hasunuma, K. and Yoshida, K.: Splitting of the subtropical gyre in the Western North Pacific, J. Oceanogr. Soc. Jpn., 34, 160-172, 1978.

Ichikawa, H., Nakamura, H., Nishina, A., and Higashi, M.: Variability of north-eastward current southeast of northern Ryukyu Islands, J. Oceanogr., 60, 351-363, 2004.

Imawaki, S., Hiroshi, U., Ichikawa, H., Fukazawa, M., Umatani, S., and ASUKA Group: Satellite altimeter monitoring the Kuroshio transport south of Japan, Geophys. Res. Lett., 28, 17-20, 2001.

Kaneko, H., Yasuda, I., Komatsu, K., and Itoh, S.: Observations of vertical turbulent nitrate flux across the Kuroshio, Geophys. Res. Lett., 40, 3123-3127, doi:10.1002/grl.50613, 2013.

Kaneko, I., Takatsuki, Y., and Kamiya, H.: Circulation of intermediate and deep waters in the Philippine Sea, J. Oceanogr., 57, 397-420, 2001.

Lie, H.-J., Cho, C.-H., Lee, J.-H., Niiler, P., and Hu, J.-H.: Separation of the Kuroshio water and its penetration onto the continental shelf west of Kyushu, J. Geophys. Res., 103, 2963-2976, 1998.

Pelegrí, J. L. and Csanady, G. T.: Nutrient transport and mixing in the Gulf Stream, J. Geophys. Res., 96, 2577-2583, 1991.

Pelegrí, J. L., Csanady, G. T., and Martins, A.: The North Atlantic Nutrient Stream, J. Oceanogr., 52, 275-299, 1996.

Wei, Y. Z., Huang, D. J., and Zhu, X.-H.: Interannual to decadal variability of the Kuroshio Current in the East China Sea from 1955 to 2010 as indicated by in-situ hydrographic data, J. Oceanogr., 69, 571-589, doi:10.1007/s10872-013-0193-5, 2013.
Williams, R. G., McDonagh, E., Roussenov, V. M., Torres-Valdes, S., King, B., Sanders, R., and Hansell, D. A.: Nutrient streams in the North Atlantic: Advective pathways of inorganic and dissolved organic nutrients, Global Biogeochem. Cy., 25, GB4008, doi:10.1029/2010GB003853, 2011.

Wunsch, C.: The North Atlantic general circulation west of $50^{\circ} \mathrm{W}$ determined by inverse methods, Rev. Geophys. Space Ge., 16, 583-620, 1978.

Yuan, Y. C., Kaneko, A., Su, J., Zhu, X.-H., Liu, Y., Gohda, N., and Chen, H.: The Kuroshio east of Taiwan and in the East China Sea and the currents east of Ryukyu Islands during early summer of 1996, J. Oceanogr., 54, 217-226, 1998.

Zhu, X.-H., Ichikawa, H., Ichikawa, K., and Takeuchi, K.: Volume transport variability southeast of Okinawa Island estimated from satellite altimeter data, J. Oceanogr., 60, 953-962, 2004.

Zhu, X.-H., Park, J.-H., Wimbush, M., and Yang, C.-H.: Comment on "Current system east of the Ryukyu Islands" by A. Nagano et al., J. Geophys. Res., 113, C03020, doi:10.1029/2007JC004458, 2008. 